\title{
Dynamic Tensile Properties and Deformational Mecha- nism of C5191 Phosphor Bronze
}

\author{
Hu Daochun ${ }^{1,2}$, Chen Minghe ${ }^{1}$ \\ ${ }^{1}$ Nanjing University of Aeronautics and Astronautics, Nanjing 210016, China; ${ }^{2}$ Taizhou Vocational \& Technical College, Taizhou 318000 , \\ China
}

\begin{abstract}
To observe the dynamic mechanical response and investigate the processes of high speed stamping for C5191 phosphorus bronze, tensile tests of $\mathrm{C} 5191$ phosphor bronze under quasi-static tensile condition at a strain rate of $0.001 \mathrm{~s}^{-1}$ by electronic universal testing machine, and dynamic tensile tests at strain rates of 500, 1000 and $1500 \mathrm{~s}^{-1}$ by split Hopkinson tensile bar (SHTB) apparatus were performed. The dynamic tensile properties and deformational mechanism were investigated by SEM and TEM. The results show that the yield strength and tensile strength of C5191 phosphor bronze under high strain rates increase by $32.77 \%$ and $11.07 \%$, respectively compared with quasi-static condition, the strain hardening index increases from 0.075 to 0.251 , and the strain rate sensitivity index for material strength changes from 0.005 to 0.022 , which presents a clear sensitivity to strain rates. The deformation resistance increases with the increasing of the strain rate due to the stronger short range resistance induced by the acceleration of dislocation motion. The ability of plastic deformation of C5191 phosphor bronze increases due to the number of movable dislocations increase significantly, multi-line slip start, and the soft effect of adiabatic temperature rise at the strain rate ranging from 500 to $1500 \mathrm{~s}^{-1}$.
\end{abstract}

Key words: C5191 phosphor bronze; dynamic tensile behavior; strain rate sensitivity; dislocation motion

C5191 phosphor bronze (equivalent to China material No.QSn6.5-0.1) is typical in its brilliance of excellent mechanical properties, high wear and corrosion resistance, low temperature resistance, inability to generate an electrical spark under impact, and good weldability, and is often used to produce metal parts like connector and pins parts ${ }^{[1]}$ in aerospace, electrical motor and appliance, and electronic information industry applications. Such metal parts were used to manufacture with the progressive stamping technology. During progressive stamping, the strain rates of the stamping material is about $10^{2} \mathrm{~s}^{-1}$, which undergoes a low strain rate deformation. Huang ${ }^{[2]}$ obtained the true stress-strain curve of QSn6.5-0.1 phosphor bronze using standard uniaxial tensile test, and used the data to investigate the high speed precision progressive stamping for the IT products. Peng et $\mathrm{al}^{[3]}$ combined tensile test and numerical simulation to determine the fracture coefficient of QSn6.5-0.1 phosphor bronze. Yu et al ${ }^{[4]}$ investigated ef- fects of deforming conditions on flowing stress and microstructure of QSn6.5-0.1 phosphor bronze with a Gleeble-1500 heat simulator. Cetinkaya ${ }^{[5]}$ studied the microscopic deformation behavior of a phosphor bronze plate during arbitrary holes piercing process.

With the rapid development of the electronics industry, the requirement for metal parts, such as thin and small, high precise and complex, is becoming more and more rigorous, and the manufacturers strive to investigate higher production speeds while maintaining high quality of the finished product. And at high speed stamping, the strain rates of material deformation are up to $10^{3} \sim 10^{4} \mathrm{~s}^{-1[6]}$. Zener et al ${ }^{[7]}$ presented the mechanical properties and deformation of materials under dynamic load conditions are different from those under static and quasi-static conditions: the increased strain rate, elastic modulus, strength, plasticity, and toughness present variations to differing extents. The deformation of a material is mainly embodied in the locality, 
non-isothermality, strong shock wave effect, etc. of deformation.

Today, the new industrial challenge consists in studying the high speed stamping impact on the material behavior, then to correctly integrate this aspect on the dynamic mechanical response. Stegeman et $\mathrm{ll}^{[8]}$ concluded that for low speed, the material response is not affected by the strain rate. But the strain rate effect significantly increases with speed. However, to the author's best knowledge, little attention was paid to the dynamic response of C5191 phosphor bronze under high strain rates deformation.

This study discussed the deformation relationships and behavior mechanism of C5191 phosphor bronze at high strain rates through quasi-static tensile test and split Hopkinson tensile bar (SHTB) dynamic tensile test in an attempt to reveal the essence of the mechanical property changes of C5191 phosphor bronze under dynamic load.

\section{Experiment}

Table 1 shows the chemical composition of the C5191-H phosphorus bronze used here; in accordance with Chinese national standards, the samples for the quasi-static tensile testing at room temperature were processed into tensile samples measuring $70 \mathrm{~mm}$ long with a diameter of $12.5 \mathrm{~mm}$, as shown in Fig.1a. Quasi-static tensile testing was carried out on an RG2000-2A microcomputer-controlled electronic universal testing machine at strain rate of $0.001 \mathrm{~s}^{-1}$; dynamic tensile testing was conducted on the SHTB at strain rates of 500, 1000, and $1500 \mathrm{~s}^{-1}$. The samples size of the HSTB is shown in Fig.1b. The scale distance section of the processed samples was polished smooth using metallographic abrasive paper to reduce the stress concentration generated by local micro-cracking and the residual stress after machine processing. The polished surface was then rinsed using alcohol.

Followed by the tensile test, samples were collected near the fracture along the tensile direction. The uniaxial tension samples were selected at different strain rates and subjected to microstructural analysis using OLYMPUS GX71 optical microscopy $(\mathrm{OM})$. The corrosion solution used was a ferric chloride hydrochloric acid alcohol solution $\left(5 \mathrm{~g} \mathrm{FeCl}_{3}+20\right.$ $\left.\mathrm{mL} \mathrm{HCl}+100 \mathrm{~mL} \mathrm{C}_{2} \mathrm{H}_{5} \mathrm{OH}\right)$. The $\mathrm{S} 4800$ Zeiss scanning electron microscope (SEM) and JEM-2100 high-resolution transmission electron microscopy (TEM) were used to observe the tensile fracture morphology and the microstructure near tensile fracture sites.

Table 1 Chemical composition of phosphor bronze C5191-H $(\mathrm{wt} \%)$

\begin{tabular}{cccccc}
\hline Sn & $\mathrm{P}$ & $\mathrm{Fe}$ & $\mathrm{Pb}$ & $\mathrm{Zn}$ & $\mathrm{Cu}$ \\
\hline $5.5 \sim 7.0$ & $0.11 \sim 0.13$ & $\leq 0.02$ & $\leq 0.05$ & $\leq 0.20$ & Bal. \\
\hline
\end{tabular}
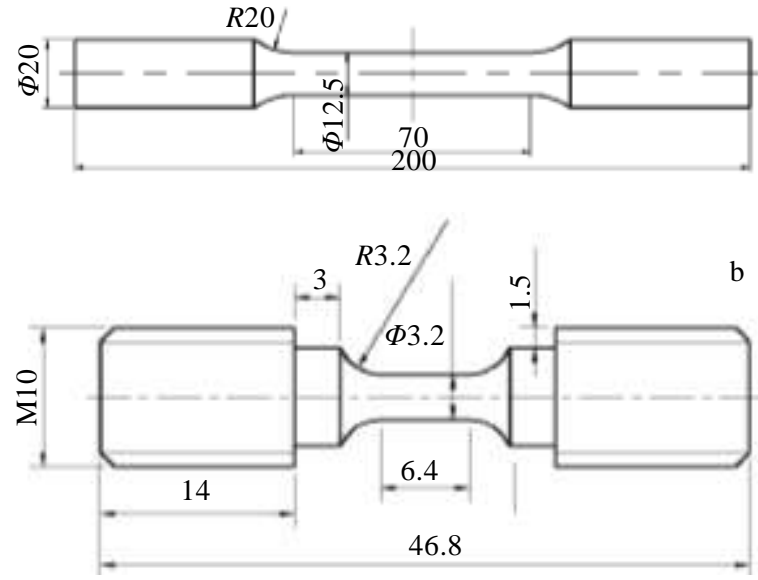

Fig.1 Geometries of tensile specimens for low strain rate (a) and high strain rate (b)

\section{Results and Discussion}

\subsection{Quasi-static and dynamic tensile mechanical properties}

Fig.2 shows the mechanical properties of C5191 phosphor bronze at room temperature and different strain rates. It can be seen that the yield strength and tensile strength of C5191 phosphor bronze under high strain rates $\left(1500 \mathrm{~s}^{-1}\right)$ increase by $32.77 \%$ and $11.07 \%$, respectively compared with quasi-static condition $\left(0.001 \mathrm{~s}^{-1}\right)$, and the strain hardening index increases from 0.075 to 0.251 . With the increase of strain rate, the tensile strength and yield strength of C5191 phosphor bronze increase significantly. However, the increase in yield strength slow gradually at high strain rate $\left(>500 \mathrm{~s}^{-1}\right)$ (Fig. 2a). Thus, the plastic deformation mechanism of C5191 phosphor bronze is alternate at high strain rates. Moreover, the dynamic deformation mechanism of C5191 phosphor bronze also fluctuates with the variations in strain rate. Compared with the strength variation, the variations of the plasticity of C5191 phosphor bronze are more complex at strain rates of $500 \mathrm{~s}^{-1}$ and above (Fig.2b). The ductility of C5191 phosphor bronze declines under dynamic tensile conditions and then increases slightly at high strain rates $\left(>500 \mathrm{~s}^{-1}\right)$. This result further proves the variations of plastic deformation and its underpinning mechanism for C5191 phosphor bronze in the case of dynamic tension. The strain hardening index $n$ is more sensitive to uniform plastic deformation and also increases during dynamic tensile testing. As an important index for evaluating the uniform plastic deformation ability of a material, this index macroscopically reflects the degree of difficulty of formation of micro-plastic deformation (such as its stress field) through the realization of slip, dislocation slip, and dislocation pile-up as extended dislocation mechanisms in the material ${ }^{[9,10]}$. 

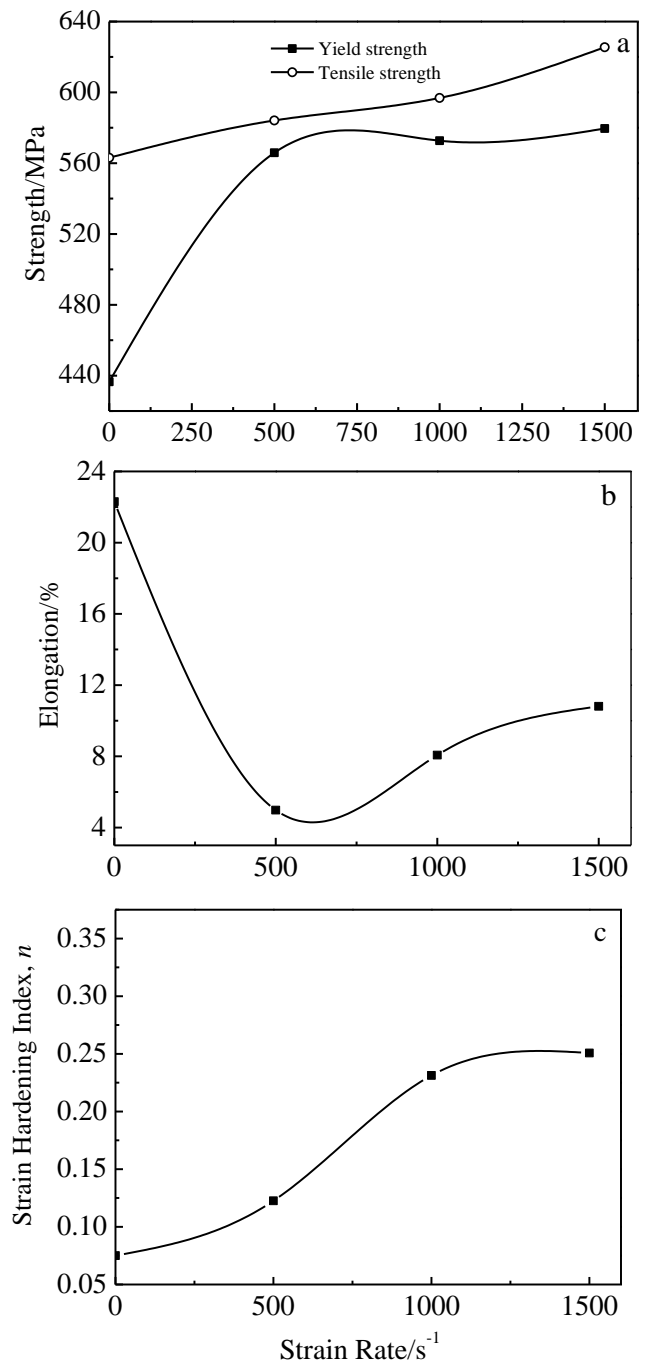

Fig.2 Tensile mechanical properties of C5191 phosphor bronze with the change of strain rates at room temperature: (a) strength, (b) elongation, and (c) strain hardening index $n$

\subsection{Quasi-static and dynamic tensile fracture mor- phology}

Fig.3 shows the tensile fracture morphologies of C5191 phosphor bronze at different strain rates. Under quasi-static tensile conditions, the tensile fractures undergo small fluctuations and present a large number of small, shallow dimples, which are indication of plastic fracture. With the increasing of strain rate, the dimples tend to become non-uniform in shape and size. The depth of big dimples increases significantly, resulting in large fluctuations of the tensile fractures.

\subsection{Strain rate sensitivity of C5191 phosphor bronze}

Fig.4 shows the stress-strain curves of C5191 phosphor bronze at room temperature, for different strain rates: the slope of the curve remains practically constant in the elastic deformation stage which suggests that the elastic modulus of C5191 phosphor bronze is insensitive to the variations in strain rate. However, with the strain rate increasing, the yield strength and tensile strength increase significantly (being consistent with results shown in Fig. 2). Thus it can be deduced that the yield strength and tensile strength are affected by the strain rate during the plastic deformation stage and are sensitive to strain rate in general.

The strain rate sensitivity index for material strength, $m$ is expressed as ${ }^{[11,12]}$ :

$$
m=\partial \ln \sigma / \partial \ln \dot{\varepsilon}
$$

where, $\sigma$ is the stress generating the same tensile strain under constant strain rate; $\dot{\varepsilon}$ is the strain rate. By substituting the stress-strain test data into equation (1), the variations of the strain rate sensitivity index $m$ of C5191 phosphor bronze with strain rate, is shown in Fig.5. It is found that the strain rate sensitivity index $m$ under high strain rates $\left(1500 \mathrm{~s}^{-1}\right)$ changes from 0.005 to 0.022 compared with quasi-static condition $\left(0.001 \mathrm{~s}^{-1}\right)$. As suggested, $m$ increases significantly with the increase of strain rate and then gradually decreases at higher strain rates $\left(>10^{3} \mathrm{~s}^{-1}\right)$. The plastic deformation of metal is closely correlated with the dislocation motion ${ }^{[13-16]}$. The variations of strain rate sensitivity signifies the changes of dislocation movement mechanism of C5191 phosphor bronze during dynamic tensile loading.

\subsection{Dislocation motion mechanism during dynamic tensile loading}

The plastic deformation of metal is mainly realized by different dislocation motions. Microscopically, it is mainly interpreted as the dislocation motion and accumulation process

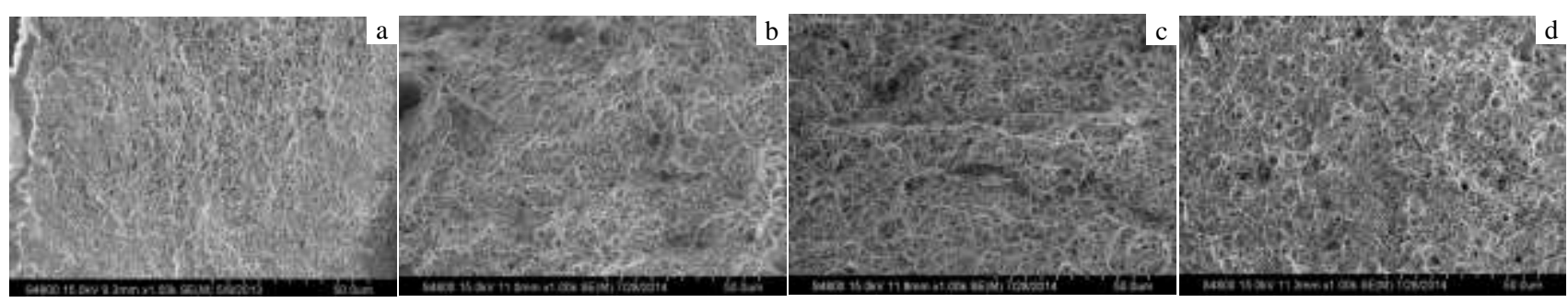

Fig.3 Tensile fractographs of C5191 phosphor bronze at different strain rates: (a) $0.001 \mathrm{~s}^{-1}$, (b) $500 \mathrm{~s}^{-1}$, (c) $1000 \mathrm{~s}^{-1}$, and (d) $1500 \mathrm{~s}^{-1}$ 


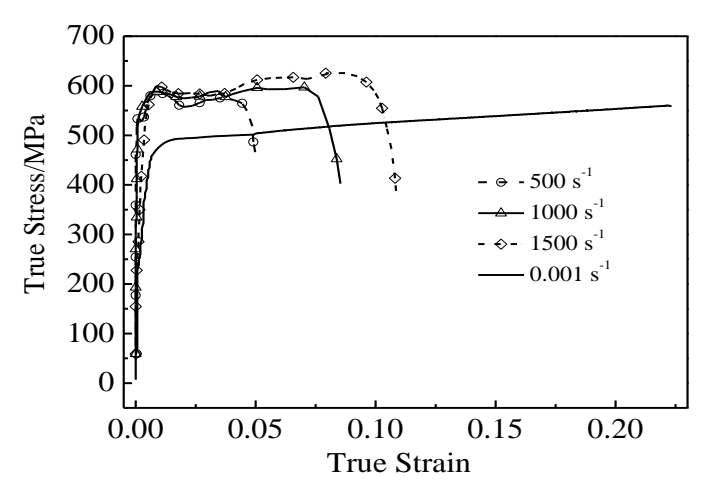

Fig.4 Tensile stress-strain curves of C5191 phosphor bronze at different strain rates

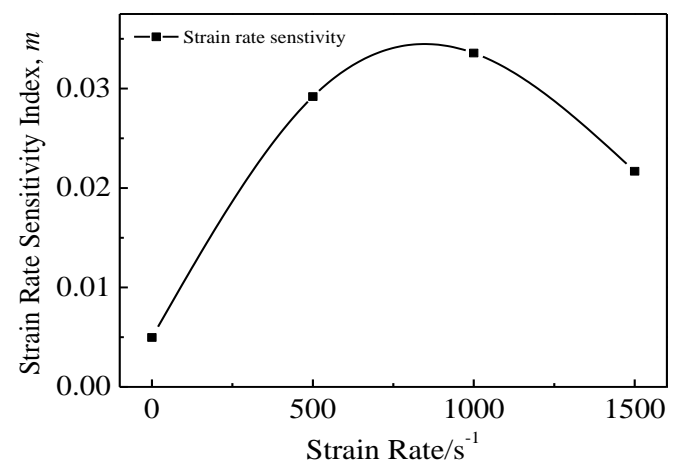

Fig.5 Variation of strain rate sensitivity index $m$ of C5191 phosphor bronze with the strain rate under rate control. The dislocation density and dislocation configuration during plastic deformation act as internal factors determining the macroscopic mechanical properties of a material. During the plastic deformation of metal, dislocation movement is continuously blocked and results in pile-up and tangling phenomena. Dislocation blocking is mainly released in forms of dissociation, climbing, etc. Moreover, compared to dislocation slip, this process needs more time to be completed ${ }^{[17,18]}$. Thus, the significant strain rate sensitivity presented by the macro-mechanical properties of C5191 phosphor bronze under dynamic tensile conditions is a result of changes in microscopic dislocation motion mechanisms during the deformation thereof.

Fig. 6 shows the dislocation configuration near the tensile fracture site in a C5191 phosphor bronze sample under different strain rates. During the quasi-static tensile test, C5191 phosphor bronze exhibits a low dislocation density (Fig. 6a). As the strain rate increases to $1000 \mathrm{~s}^{-1}$, the dislocation density increases significantly, accompanying the formation of pile-up and tangling on the grain boundaries (Fig.6c, 6d). Under quasi-static tensile conditions, the movable dislocation of C5191 phosphor bronze basically remains constant under material deformation and leaves enough time to realize the acceleration process and release dislocation blocking. Therefore, the material has a low strength but a high plasticity at low strain rates. On one hand, with the increase of strain rate, dislocations motion in the material are accelerated. As a result, more dislocations should be driven per unit time. The interaction of the dislocations gives rise to dislocation pile-up, dislocation tan-
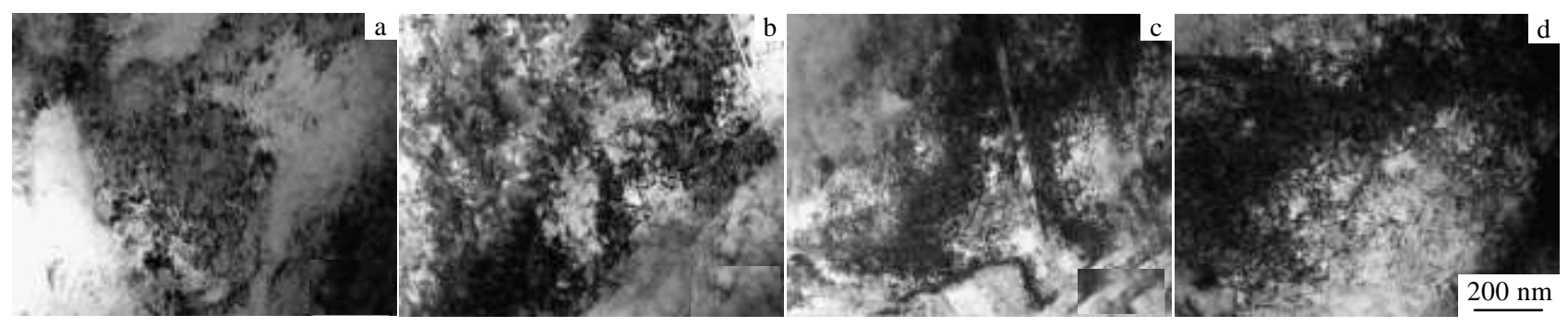

Fig.6 Dislocation configurations near the fracture tip of C5191 phosphor bronze after tensile test at different strain rates: (a) $0.001 \mathrm{~s}^{-1}$; (b) $500 \mathrm{~s}^{-1}$; (c) $1000 \mathrm{~s}^{-1}$; (d) $1500 \mathrm{~s}^{-1}$

gling, and immovable jog ${ }^{[19]}$ (Fig.6c, 6d), and a gradual increase in flow stress. Studies have shown that ${ }^{[20,21]}$, the dislocation in the material accelerates with the increase of strain rate under dynamic load conditions. Meanwhile, "short range factors" (such as the Peierl-Nabarro force between lattices, the atomic thermal vibration resistance, atomic extra-nuclear electron cloud resistance) that block dislocations are significantly enhanced. These factors strengthen the resistance to dislocation motion. Consequently, the strength of C5191 phosphor bronze is signifi- cantly improved under dynamic tensile conditions (Fig. 2a); On the other hand, with the increasing of strain rate, the dislocation disassociation and climbing appear to be time-dependent and leaves no time to release the pile-up, tangling, and local stress concentration formed by dislocation blocking. In this case, the plastic deformation mechanism of the material is no longer coordinated by the release of dislocation pile-up, crystal rotation, a geometrically necessary boundary (GNB), etc. Instead, micro-voids and micro-cracks take part in the material, leading to 
non-uniform deformation. Therefore, the plasticity (elongation) of the material is lower under dynamic tensile conditions compared to that under quasi-static conditions (as shown in Fig.2b).

In high strain rate tensile processes, dislocation in the C5191 phosphor bronze crystal is subjected to high tensile shear stress for a short period. Meanwhile, the dislocation on a conventional slip system has probably not been opened in such a short time. However, the high tensile shear stress has reached, or exceeded the critical shear stresses of multiple slip systems and opened a multi-system slip ${ }^{[22,23]}$. Therefore, the plasticity of C5191 phosphor bronze increases at high strain rates. Simultaneously, the number of dislocations in C5191 phosphor bronze increases and the capability for plastic deformation strengthens. However, dislocation resistance still grows with the increase of strain rate. The increase of movable dislocations also gives rise to a high rate of dislocation pile-up and tangling and produces obvious strain hardening (reflecting the significant increase of the strain hardening index, as shown in Fig.2c). This phenomenon further increases the dislocation resistance and the strength of the material. In addition, due to localization and non-isothermality during dynamic high-speed tensile loading, the heat generated by strain may not be dissipated totally in such a short time and thus lead to an adiabatic temperature rise manifested as a local temperature rise. The thermal softening effect formed thereby can reduce dislocation resistance and strain hardening and promote plasticity $^{[24-26]}$. Overall, the plastic deformation of C5191 phosphor bronze at high strain rates is an inter-influencing and competitive process of strain hardening, strain rate strengthening, and that softening induced by the aforementioned adiabatic temperature rise. Macroscopically, the process is embodied as a synchronous elongation increase with the gradual rise of strength and straining hardening index. On a microscopic level, it is a reflection of the continuous increase of dislocation tangling and pile-up. The multi-system slip and thermal softening during the dynamic deformation process play a role in regulating the plastic deformation and alleviating the dislocation resistance triggered by strain rate increase.

\section{Conclusions}

1) In dynamic tensile tests at a high strain rate, C5191 phosphor bronze presents strength and plasticity increment to varying degrees and exhibits sensitivity to strain rate.

2) During dynamic tensile loading at high strain rate, C5191 phosphor bronze is localized and generates a large number of dislocations in a short time. The dislocations give rise to dislocation pile-up and tangling affected by "short range resistance". Subsequently, micro-voids and micro-cracks form locally and lead to non-uniform deformation of the material.
3) The dislocation motion velocity and dislocation motion resistance increase in dynamic tension at high strain rate. The deformation resistance of C5191 phosphor bronze increases with the increasing of strain rate. At the same time, the plasticity of C5191 phosphor bronze under high-strain rate dynamic tension is improved by the significantly increased amount of movable dislocations, the opening of multiple slip systems, as well as the adiabatic temperature rise to some extent.

\section{References}

1 Liu Ping, Ren Fengzhang, Jia Shuguo. Copper Alloy and Its Application[M]. Beijing: Chemical Industry Press, 2007: 73 (in Chinese)

2 Huang Zhenyuan. Research the Key Technology in the High Speed Precision Progressive Stamping for the IT Products[D]. Guangzhou: South China University of Technology, 2007: 64 (in Chinese)

3 Peng Yanhua, Huang Zhenyuan, Qiu Hongyang. Journal of the Institute of Metals[J], 2007, 36: 55 (in Chinese)

4 Yu Xingzhe, Liu Zheng. Journal of Southern Institute of Metallurgy [J], 2004, 25: 10 (in Chinese)

5 Cetinkaya K. Materials \& Design[J], 2007, 28: 294

6 Subramonian S. Improvement of Punch and Die Life and Part Quality in Blanking of Miniature Parts[D]. Columbus: The Ohio State University, 2013.

7 Zener C, Hollomon J H. Journal of Applied physics[J], 1944, 15(1): 22

8 Stegeman Y M, Goijaerts A M, Brokken D et al. Journal of Materials Processing Technology[J], 1997, 87(1): 266

9 Yalcinkaya T, Brekelmans W A M, Geers M G D. Journal of the Mechanics and Physics of Solids[J], 2011, 59:

10 Peng Jian, Zhou Changyu, Dai Qiao et al. Rare Metal Materials and Engineering [J], 2013, 42(3): 483 (in Chinese)

11 Song Yuquan, Guan Zhiping, Li Zhigang et al. Science in China(Series E) [J],2007, 37: 1363 (in Chinese)

12 Castany P, Pettinari-Sturmel F, Crestou J et al. Acta Materialia[J], 2007, 55: 6284

13 Zhou Zhiming, Sun Yanrui. Chinese Science Bulletin[J], 2004, 49: 1123 (in Chinese)

14 Horvath G, Chinh N Q, Gubicza J et al. Materials Science and Engineering $A[\mathrm{~J}], 2007,445-446: 186$

15 Li Zaijiu, Yang Tianwu, Jin Qinglin et al. Rare Metal Materials and Engineering $[\mathrm{J}], 2014$, 43(11): 2609 (in Chinese)

16 Vinogradov A, Maruyama M, Kaneko Y et al. Philosophical Magazine [J], 2012, 92: 666

17 Dmitriev S V, Nazarova A A, Pshenichnyuk A I et al. Dynamics[J], 2011, 4: 1079

18 Meyers M A, Iii G T G, Thadhani N N. Journal of the Minerals, Metal \& Materials Society[J], 2010, 62(1): 14

19 Johnston W G, Gilman J J. Journal of Applied Physics[J], 1959, 30: 129

20 Dong Danyang, Liu Yang, Wang Lei et al. Acta Metallurgica 
Sinica $[\mathrm{J}], 2013,49: 159$ (in Chinese)

21 Sui Xian, Song Baoyun, Li Bing et al. The Chinese Journal of Nonferrous Metals[J], 2009, 19(6): 1049 (in Chinese)

22 Dai Qifeng, Song Renbo, Fan Wuyan et al. Acta Metallurgica Sinica[J], 2012, 48(10): 1160 (in Chinese)

23 Ding Y T, Liu B, Guo T B et al. The Chinese Journal of Nonferrous Metals[J], 2014, 24(8): 2057
24 San X Y, Liang X G, Cheng L P et al. Transactions of Nonferrous Metals Society of China[J], 2012, 22(4): 819

25 Li G M, Li D R, Ni X J et al. Rare Metal Materials and Engineering[J], 2013, 42(7): 1352

26 Lee D J, Yoon E Y, Ahn D H et al. Acta Materialia[J], 2014, 76: 281

\title{
C5191 磷青铜的动态拉伸性能和变形机制
}

\author{
胡道春 ${ }^{1,2}$, 陈明和 ${ }^{1}$ \\ (1. 南京航空航天大学, 江苏 南京 210016) \\ (2. 台州职业技术学院，浙江 台州 318000)
}

摘 要: 为了探讨C5191磷青铜在高应变速率条件下的动态响应, 解决高速冲压工艺问题, 利用电子万能材料试验机和分离式Hopkinson 拉杆装置对C5191磷青铜分别进行应变速率为0.001和500、1000、1500 $\mathrm{s}^{-1}$ 的准静态和动态拉伸试验, 结合SEM和TEM等手段, 研究了 C5191 磷青铜的动态拉伸性能及其变形机制。结果表明: C5191磷青铜高应变速率动态拉伸与准静态条件相比较, 其屈服强度和抗拉强度分别 提升了 $32.77 \%$ 和 $11.07 \%$; 应变硬化指数由 0.075 增加到 0.251 ; 材料强度的应变速率敏感指数由 0.005 变化到 0.022 , 呈现出明显的应变速率 敏感性; 高应变速率动态拉伸过程中, 位错运动速度加快, 导致位错 “近程阻力” 加大, 使C5191磷青铜的变形抗力随着应变速率的增 加而增大。可动位错数量的显著增多, 多系滑移的开启, 以及绝热温升软化效应在一定程度上提高了 C5191磷青铜高应变速率动态拉伸 时的塑性。

关键词: C5191 磷青铜; 动态拉伸行为; 应变速率敏感性; 位错运动

作者简介: 胡道春, 男, 1977 年生, 博士生, 南京航空航天大学机电学院, 江苏 南京 210016, 电话: 025-84892508, E-mail: 13736588306@163.com 